\title{
DEGRADABILIDADE E DIGESTIBILIDADE DA FORRAGEM CONSUMIDA POR OVINOS EM PASTAGENS ANUAIS DE INVERNO
}

\author{
Paulo Rossi Junior'1, Sergio Rodrigo Fernandes'1, Viviane Cristina Luczyszyn², \\ Giovana Fanchin Zanetti', Maurício Giovani Oikawa ${ }^{2}$
}

\author{
1 UFPR \\ 2 Autônomos \\ Correspondência: Paulo Rossi Junior: parossi@ufpr.br
}

\begin{abstract}
RESUMO: Objetivou-se avaliar a degradabilidade ruminal in situ e a digestibilidade in vitro da forragem consumida por ovinos em pastagens formadas exclusivamente por azevém anual (Lolium multiflorum Lam., Tratamento 1), aveia preta (Avena strigosa Schreb., Tratamento 2) e pelo consórcio entre as duas espécies (Tratamento 3). Três carneiros mestiços Suffolk, com 18 meses de idade e $70 \mathrm{~kg}$ de PC em média, foram implantados com cânulas esofágicas e utilizados para coletar as amostras de forragem. O método de pastejo foi de lotação contínua com carga animal variável, sendo a pressão de pastejo ajustada para manter a oferta de forragem de $7 \%$ do PC em MS/dia. Os três animais foram submetidos ao mesmo tratamento em intervalos de três dias, e passaram nove vezes em cada tratamento. Alíquotas das amostras de extrusa foram submetidas a análises para determinação dos teores de MS, PB e FDN. Posteriormente foram analisados os parâmetros de degradação ruminal in situ e a digestibilidade in vitro destas frações. A degradabilidade ruminal da MS, PB e FDN mostrou-se consistente com as características e ao estádio fenológico das pastagens, sendo superiores para o azevém, intermediários para a pastagem consorciada e inferiores para a aveia. Variações nas características das pastagens e mudanças no comportamento de seleção da forragem pelos animais em pastejo determinaram alta variabilidade na digestibilidade in vitro da MS, PB e FDN. Valores superiores para digestibilidade in vitro da MS e FDN foram registradas para o azevém, refletindo a melhor qualidade desta espécie comparada a aveia no inveno. A maior digestibilidade in vitro da PB na pastagem consorciada esteve associada a presença do azevém em estádio vegetativo e da aveia em estádio de florescimento em sua composição.

Palavras-chave: aveia preta; azevém anual; cânulas esofágicas; extrusa; pastejo
\end{abstract}

\section{DEGRADABILITY AND DIGESTIBILITY OF FORAGE CONSUMED BY SHEEP IN ANNUAL WINTER PASTURES}

\begin{abstract}
The study was designed to investigate the in situ degradability and in vitro digestibility of forage ingested by sheep grazing on pastures composed exclusively by annual ryegrass (Lolium multiflorum Lam., Treatment 1), black oats (Avena strigosa Schreb., Treatment 2) and mixed of both species (Treatment 3). Three crossbred Suffolk rams, 18 months age and $70 \mathrm{~kg} \mathrm{BW}$, were implanted with esophageal cannulas and used to collect the forage samples. The grazing method was continuous with variable stocking and grazing pressure was adjusted to maintain the forage supply in $7 \%$ BW in DM. $d^{-1}$. The three rams were allocated in the same treatment every three days and submitted to each treatment nine times. Aliquots from extrusa were analyzed for determination of DM, $\mathrm{CP}$ and NDF levels. Subsequently the samples were submitted to in situ degradability and in vitro digestibility analysis. The degradability of DM, CP and NDF was consistent to the characteristics and the developmental stage of the pastures, and were higher for ryegrass, intermediate for the mixed pasture and lower for black oats. Variations in characteristics of pastures and changes in behavior selection of forage by grazing animals determined high variability to in vitro digestibility of DM, CP and NDF. Higher values for in vitro digestibility DM and NDF were presented in annual ryegrass, which demonstrated the high quality of this specie compared to black oats in winter. The highest in vitro digestibility of $\mathrm{CP}$ in mixed pasture was associated with the presence of ryegrass at the vegetative stage and the black oats in the flowering stage on ingested forage.
\end{abstract}

Key Words: annual ryegrass; black oats; esophageal cannulas; extrusa; grazing 


\section{INTRODUÇÃO}

A aveia preta (Avena strigosa Schreb.) e o azevém anual (Lolium multiflorum Lam.) são as principais espécies forrageiras utilizadas na formação de pastagens anuais de inverno na Região Sul do Brasil. Cultivadas de forma isolada ou em consórcio, estas espécies apresentam resistência ao pisoteio e produção de forragem com teores elevados de proteína bruta e de alta digestibilidade (Macari et al., 2006; Arboitte et al., 2006). Na produção de ovinos, a utilização de pastagens formadas exclusivamente por azevém no inverno e na primavera tem favorecido a obtenção de resultados satisfatórios de desempenho animal e econômico (Ribeiro et al., 2009; Barros et al., 2009).

No Brasil, a maioria dos sistemas de produção de ovinos é baseada na exploração de pastagens, que correspondem à principal fonte de nutrientes para os animais. Nessa condição, a determinação da quantidade e da qualidade da forragem consumida pelos animais constitui um desafio, e diferentes métodos têm sido desenvolvidos para obter estas informações de forma acurada. Estimativas da qualidade da forragem ingerida em pastejo têm sido realizadas em amostras colhidas por simulação de pastejo (Burns et al., 1989) ou para determinação da massa de forragem na pastagem (Arboitte et al., 2006).

$\mathrm{Na}$ tentativa de aumentar a acurácia destas estimativas, passou-se a utilizar animais implantados com cânulas esofágicas (Cook et al., 1958; Bishop e Froseth, 1970). Neste método, a estimativa da qualidade da forragem selecionada e consumida pelos animais é realizada em amostras colhidas diretamente no esôfago, sendo estas denominadas extrusas. Trabalhos recentes mostram que este método é confiável para estimar a composição morfológica (Trindade et al., 2007) da dieta selecionada sob pastejo. Além disso, a possibilidade de realizar análises sequenciais de degradabilidade ruminal e digestibilidade das extrusas permite compreender de forma dinâmica como ocorre o aproveitamento de nutrientes pelos animais em pastejo.

Neste contexto, objetivou-se avaliar a degradabilidade ruminal in situ e a digestibilidade in vitro da forragem consumida por ovinos em pastagens anuais de inverno.

\section{MATERIAL E MÉTODOS}

O experimento foi conduzido no Laboratório de Produção e Pesquisa em Ovinos e Caprinos (LAPOC), da Universidade Federal do Paraná (UFPR), localizado em Pinhais-PR (2525'S, 498'W, $930 \mathrm{~m}$ altitude). O solo é classificado como Latossolo Vermelho Amarelo, de textura argilosa, com relevo suave ondulado (EMBRAPA, 1999). O período experimental se estendeu de Julho a Setembro/2001.

As pastagens foram implantadas no início de Julho/2001 e constituíram três áreas de aproximadamente 1 ha, uma formada de azevém anual (Lolium multiflorum Lam., Tratamento 1), uma formada de aveia preta (Avena strigosa Schreb., Tratamento 2) e uma consorciada de aveia preta e azevém anual (Tratamento 3). Para formação da pastagem de azevém anual utilizaramse $45,5 \mathrm{~kg} / \mathrm{ha}$ de sementes, para a pastagem de aveia preta $100 \mathrm{~kg} / \mathrm{ha}$ de sementes e para pastagem consorciada utilizaram-se $60 \mathrm{~kg} / \mathrm{ha}$ de sementes de aveia preta e $35 \mathrm{~kg} / \mathrm{ha}$ de sementes de azevém anual.

Aos 40 dias pós-plantio foi realizada adubação de cobertura nas áreas com aplicação única de $100 \mathrm{~kg} / \mathrm{ha}$ de nitrogênio na forma de uréia. Após 20 dias da adubação de cobertura (60 dias pós-plantio) teve início o período de pastejo. 
Utilizaram-se três ovinos machos mestiços Suffolk implantados com cânulas esofágicas, que apresentavam 18 meses de idade e $70 \mathrm{~kg}$ de peso corporal (PC), em média. A implantação da cânula esofágica foi feita conforme a técnica descrita por Bishop e Froseth (1970), e teve como objetivo possibilitar a colheita de amostras da dieta consumida pelos animais. Foi adaptada uma bolsa coletora em cada animal, presa por presilhas ao longo do pescoço, que tinha a função de coletar parte do material consumido (extrusa) e separá-lo da saliva pelo fundo telado.

O método de pastejo foi de lotação contínua com carga animal variável, onde a pressão de pastejo foi ajustada para manter a oferta de forragem de $7 \%$ do PC em matéria seca (MS)/dia. O ajuste da pressão de pastejo foi realizado utilizando-se animais reguladores e a disponibilidade de forragem foi determinada pelo método do quadrado (Gardner, 1986).

O início da coleta de extrusa foi em 09/09/2001 no tratamento azevém anual, em 10/09/2001 no tratamento aveia preta e em 11/09/2001 no tratamento consorciado. As coletas foram sequênciais a cada três dias no mesmo tratamento. Os animais passaram nove vezes por cada tratamento e houve o descarte de dois dias de colheita por tratamento. Portanto, foram realizadas sete colheitas por tratamento que, considerando três tratamentos e três animais coletores, resultou em 63 amostras de extrusa.

Após a secagem a $65^{\circ} \mathrm{C}$ e trituração de toda a extrusa, alíquotas de cada amostra foram submetidas às análises laboratoriais para determinação da proteína bruta (PB) e fibra em detergente neutro (FDN), conforme descrito por Pereira e Rossi Junior (1995). Após a retirada das alíquotas, as amostras de extrusas foram incubadas no rúmen de quatro ovinos previamente preparados com fístula ruminal (Harrison, 1995). Os animais permaneceram confinados em baias individuais e foram alimentados com feno de alfafa.

Conforme descrito por Pereira e Rossi Junior (1995), a incubação ruminal foi realizada utilizando-se sacos de náilon de 40 micras, com $10 \mathrm{~cm}$ de comprimento e $7 \mathrm{~cm}$ de largura (área total de $70 \mathrm{~cm}^{2}$ ). Sacos de náilon contendo $1,5 \mathrm{~g}$ de amostra foram incubados por períodos préestabelecidos de $0,2,4,6,8,12,36$ e 72 horas. Para cada tratamento foram determinados os seguintes parâmetros de degradação ruminal in situ da MS, PB e FDN: frações solúvel (A), potencialmente degradável (B) e indegradável (C); velocidade de desaparecimento (c); degradabilidade potencial (DEPOT) e efetiva (DEEF).

Para determinação da digestibilidade in vitro utilizou-se a técnica descrita por Tilley e Terry (1963). As 63 amostras de extrusas foram analisadas em triplicatas, resultando em 189 análises realizadas.

Os dados de degradabilidade ruminal foram submetidos à análise de variância pelo modelo linear geral (GLM) em delineamento inteiramente casualizado, com três tratamentos e quatro repetições, e as médias obtidas para cada fração comparadas entre os tratamentos pelo teste de Tukey a $5 \%$ de significância. Os dados de digestibilidade in vitro foram submetidos à análise de regressão, onde foram correlacionados os dias de pastejo com a digestibilidade das frações estudadas. Todos os dados foram analisados utilizando-se o programa STATISTICA 6.0 .

\section{RESULTADOS E DISCUSSÃO}

\section{Degradabilidade}

A aveia apresentou menor fração solúvel e maior fração indegradável da 
MS, o que resultou em menor fração potencialmente degradável da MS comparada $(\mathrm{P}<0,05)$ aos demais tratamentos (Tabela 1). Isto ocorreu provavelmente em função da baixa qualidade da pastagem de aveia, que apresentou baixa relação folha:colmo em virtude de seu estádio fenológico avançado. $\mathrm{O}$ aumento do teor de FDN é atribuído ao maior desenvolvimento de colmos na pastagem, componente morfológico com menor potencial de degradabilidade que as lâminas foliares (Paciullo, 2002). Foi observado teor de $58,3 \%$ para FDN na pastagem de aveia, valor superior as demais que apresentaram média de $52,6 \%$ de FDN, conforme relatado por Luczyszyn e Rossi Junior (2007).

\begin{tabular}{|c|c|c|c|c|c|c|c|}
\hline \multirow{2}{*}{\multicolumn{2}{|c|}{ Tratamento }} & \multicolumn{6}{|c|}{ Parâmetros de Degradação Ruminal } \\
\hline & & $\begin{array}{c}\text { A } \\
(\%)\end{array}$ & $\begin{array}{c}\mathrm{B} \\
(\%)\end{array}$ & $\begin{array}{c}\mathrm{C} \\
(\%)\end{array}$ & $\begin{array}{c}c c \\
(\% h)\end{array}$ & $\begin{array}{c}\text { DEPOT } \\
(\%)\end{array}$ & $\begin{array}{c}\text { DEEF } \\
(\%)\end{array}$ \\
\hline \multirow{3}{*}{$\cong$} & Azevém & $37,23 a$ & $43,86 a$ & $18,91 \mathrm{~b}$ & 7,82 & $80,93 a$ & 63,97 a \\
\hline & Aveia & $33,03 \mathrm{~b}$ & $37,01 \mathrm{~b}$ & 29,96 a & 8,25 & $69,94 \mathrm{~b}$ & $56,05 \mathrm{~b}$ \\
\hline & Aveia + Azevém & $36,76 a b$ & $40,80 \mathrm{a}$ & $22,44 \mathrm{~b}$ & 7,34 & 77,31 a & $60,93 \mathrm{ab}$ \\
\hline \multirow{3}{*}{$\stackrel{\infty}{a}$} & Azevém & 41,89 a & $54,52 \mathrm{c}$ & 3,59 & 8,05 a & 96,22 & $75,50 \mathrm{a}$ \\
\hline & Aveia & $31,26 \mathrm{~b}$ & 64,41 a & 4,33 & $5,82 \mathrm{~b}$ & 94,57 & $65,80 \mathrm{~b}$ \\
\hline & Aveia + Azevém & $38,02 a$ & $59,14 b$ & 2,84 & $7,83 a$ & 96,88 & 73,91 a \\
\hline \multirow{3}{*}{ zo } & Azevém & & $87,93 a$ & $12,07 \mathrm{~b}$ & $3,56 \mathrm{a}$ & $81,11 \mathrm{a}$ & $36,57 \mathrm{a}$ \\
\hline & Aveia & & $77,53 \mathrm{~b}$ & 22,47 a & $2,18 \mathrm{c}$ & $61,20 \mathrm{c}$ & $23,52 \mathrm{c}$ \\
\hline & Aveia + Azevém & & $83,55 \mathrm{a}$ & $16,45 \mathrm{~b}$ & $2,87 \mathrm{~b}$ & $72,90 \mathrm{~b}$ & $30,45 \mathrm{~b}$ \\
\hline
\end{tabular}

No entanto, verificou-se valor superior $(P<0,05)$ para a fração potencialmente degradável da PB na aveia, que está relacionado ao acúmulo deste nutriente na inflorescência. Ferolla et al. (2008) relataram resposta semelhante em aveia preta submetida à pastejo com bovinos, onde observaram elevados teores da fração solúvel e potencialmente degradável da PB mesmo com alta proporção de inflorescências na pastagem.

As taxas de desaparecimento da $P B$ e da FDN foram inferiores $(P<0,05)$ para a aveia (Tabela 1), o que é explicado pelos maiores teores de FDN da forragem consumida pelos animais neste tratamento. Os teores elevados de FDN estão associados à presença de tecidos como o xilema e de células da bainha interna dos feixes vasculares no colmo, que são resistentes a degradação no rúmen (Paciullo, 2002). Isso é confirmado pelos valores inferiores $(P<0,05)$ observados para degradabilidade potencial da MS e da FDN na forragem consumida na pastagem de aveia. A maior participação de componentes e tecidos estruturais nesta pastagem influenciou, também, a degradabilidade efetiva da $\mathrm{PB}, \mathrm{MS}$ e FDN, que foram inferiores $(P<0,05)$ ao azevém (Tabela 1$)$. Santos et al. (2009) verificaram resposta semelhante para degradabilidade potencial e efetiva da MS, PB e FDN na forragem consumida por ovinos mantidos em pastejo na caatinga nos períodos seco e chuvoso, onde ocorre variação do estádio fenológico da vegetação.

A presença da aveia na pastagem consorciada influenciou $(P<0,05)$ a taxa de desaparecimento e a degradabilidade potencial e efetiva da FDN na forragem consumida pelos animais, o que resultou em valores intermediários para estes parâmetros em relação aos demais tratamentos (Tabela 1). Por outro lado, o azevém determinou valores superiores para taxa de desaparecimento e degradabilidade efetiva da PB da forragem consumida na pastagem consorciada, que foram semelhantes $(P>0,05)$ a pastagem de azevém. Isso é atribuído a maior fração solúvel da PB associada ao elevado teor deste nutriente no azevém, que correspondeu a 21\%, em média (Luczyszyn e Rossi Junior, 2007). O elevado teor de PB indica que esta espécie apresentou alta relação folha:colmo, o que caracteriza uma das condições de maior preferência no processo de seleção e consumo de forragem em pastejo, conforme demonstrado em trabalhos conduzidos 
com outras espécies de herbívoros domésticos em pastagens cultivadas tropicais (Brâncio et al., 2003; Silva et al., 2009) e anuais de inverno (Trevisan et al., 2004; Bratti et al., 2009). Portanto, a maior participação de azevém na composição da forragem consumida explica a obtenção de resultados semelhantes $(P>0,05)$ entre a pastagem consorciada e de azevém para as frações solúvel, potencialmente degradável e insolúvel, e para degradabilidade potencial e efetiva da MS.

\section{Digestibilidade}

Registrou-se alta variabilidade nos resultados obtidos para digestibilidade da MS, PB e FDN da forragem consumida pelos animais durante 0 experimento, independente da pastagem avaliada (Figura 1). $\mathrm{O}$ comportamento destas variáveis em função do período experimental e ajustadas para cada tratamento é descrito pelas equações apresentadas na Tabela 2.

Os valores obtidos para digestibilidade da MS da forragem oscilaram entre 38 e $68 \%$ nos tratamentos avaliados (Figura 1). As diferenças entre os estádios fenológicos da aveia e do azévem influenciaram a digestibilidade da MS da forragem consumida nestes tratamentos, que apresentou média de 55 e 58\% respectivamente. A digestibilidade da MS da forragem consumida na pastagem consorciada apresentou média de $55 \%$, mantendo-se próxima da aveia.

A digestibilidade da PB da forragem consumida variou entre $31 \mathrm{e}$ $62 \%$ nos tratamentos avaliados (Figura 1). A baixa proporção de folhas na pastagem de aveia determinou valor inferior para digestibilidade da PB da forragem consumida nesta pastagem comparada ao azevém, com média de 41 e $49 \%$ respectivamente. No entanto, a maior fração solúvel e potencialmente degradável da PB da forragem consumida na pastagem consorciada determinou maior digestibilidade da PB, que correspondeu à média de $53 \%$.

A FDN foi 0 nutriente que apresentou maior variação de digestibilidade, assumindo valores entre 20 e $71 \%$ nos tratamentos avaliados (Figura 1). A maior proporção de colmos e, por consequência, de tecidos estruturais de baixa degradabilidade determinou digestibilidade inferior da FDN na forragem consumida na pastagem de aveia comparada ao azevém, apresentando valores médios de 40 e 50\%, respectivamente. A digestibilidade da FDN da forragem consumida na pastagem consorciada apresentou valor intermediário, com média de $43 \%$.
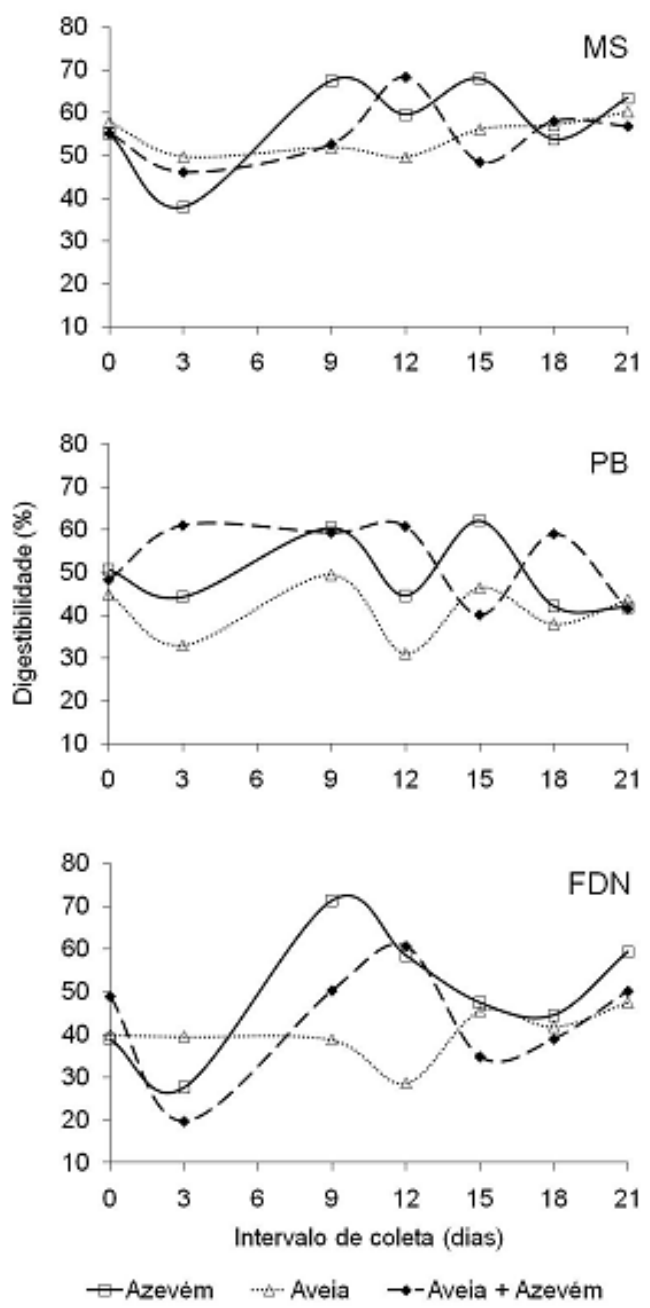

Figu ra 1 - Digestibilidade in vitro da matéria seca (MS), proteína bruta (PB) e fibra em detergente neutro (FDN) da forragem consumida por ovinos em pastagens de azevém anual, aveia preta e consorciada de aveia preta e azevém anual. 


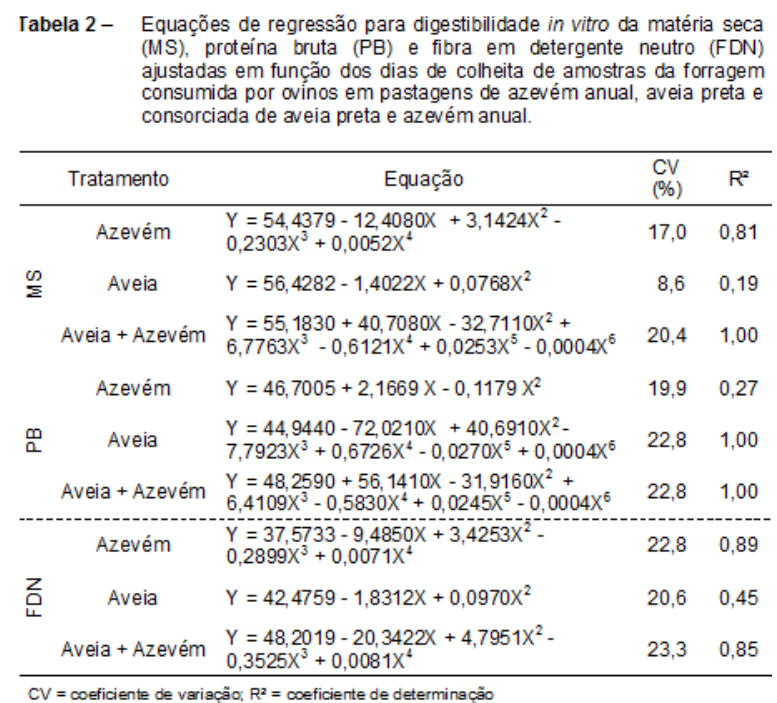

A variabilidade dos resultados de digestibilidade das frações analisadas é explicada pelas diferenças observadas entre as características estruturais, morfológicas e qualitativas das pastagens avaliadas, e também pelas componentes relacionadas ao comportamento de pastejo dos animais. Mudanças no padrão de busca, seleção e apreensão da forragem ocorrem de forma dinâmica no espaço e no tempo, e definem a qualidade da forragem colhida por animais em pastejo, conforme relatado para caprinos (Silva et al., 2009), bovinos (Trindade et al., 2007) e equinos (Dittrich et al., 2007). Bazely (1990) demonstrou que ovinos buscam maximizar o consumo de forragem ao selecionarem plantas mais altas, e manter a ingestão de nitrogênio em níveis adequados ao selecionarem plantas mais escuras, que são indicadoras de elevados níveis de nitrogênio e carboidrato solúvel.

A complexidade dinâmica e a gama de fatores que interferem no processo de pastejo explicam a variabilidade dos resultados obtidos para digestibilidade da MS, PB e FDN da forragem consumida por ovinos nas pastagens avaliadas. Isso justifica a obtenção de resposta significativa $(\mathrm{P}<0,05)$ e de maior acurácia apenas para equações polinomiais de grau elevado (igual ou superior a 4) para estimar e descrever o comportamento da digestibilidade das frações analisadas em função do período experimental. Destaca-se que devido à maior complexidade, as estimativas de digestibilidade da MS, PB e FDN da forragem consumida na pastagem consorciada devem ser obtidas por equações polinomiais de grau superior aquelas utilizadas nas pastagens formadas exclusivamente por azevém ou aveia.

Apesar da alta variabilidade, as estimativas da digestibilidade da forragem consumida em pastejo a partir de amostras colhidas em fistulas esofágicas tendem a ser mais acuradas do que aquelas realizadas a partir amostras colhidas diretamente da pastagem ou por simulação de pastejo (Burns et al., 1989). Ambos os métodos subestimam 0 potencial de discriminação e seleção dos componentes morfológicos e botânicos da pastagem, o que determina menor variabilidade e acurácia da digestibilidade das frações analisadas, conforme observado por Arboitte et al. (2006) e Macari et al. (2006).

\section{CONCLUSÃO}

A degradabilidade ruminal das amostras colhidas em cânulas esofágicas de ovinos foi superior para 0 azevém, intermediária para a pastagem consorciada e inferiores para a aveia. Valores superiores para digestibilidade in vitro da MS e FDN foram registradas para o azevém, refletindo a melhor qualidade desta espécie em comparação à aveia. $A$ maior digestibilidade in vitro da PB foi na pastagem consorciada e está associada a presença do azevém em estádio vegetativo e da aveia em estádio de florescimento em sua composição. 


\section{REFERÊNCIAS}

ARBOITTE, M.Z.; RESTLE, J.; BRONDANI, I.L. et al. Pastejo contínuo ou temporário e suplementação energética em pastagem cultivada de inverno no desempenho de bezerros. Acta Scientiarum Animal Science, v.28, n.4, p.453-459, 2006.

BARROS, C.S.; MONTEIRO, A.L.G.; POLI, C.H.E.C. et al. Resultado econômico da produção de ovinos para carne em pasto de azevém e confinamento. Acta Scientiarum Animal Sciences, v.31, n.1, p.77-85, 2009.

BAZELY, D.R. Rules and cues used by sheep foraging in monocultures. In: HUGHES, R.N. (Ed.) Behavioral mechanisms of food selection. Berlin: NATO ASI Series, 1990. p.343-366.

BISHOP, J.P.; FROSETH, J.A. Improved techniques in esophageal fistulization of sheep. American Journal of Veterinary Research, v.31, n.8, p.1505-1507, 1970.

BRÂNCIO, P.A.; NASCIMENTO JR, D.; EUCLIDES, V.P.B. et al. Avaliação de três cultivares de Panicum maximum Jacq. sob pastejo: composição da dieta, consumo de matéria seca e ganho de peso animal. Revista Brasileira de Zootecnia, v.32, n.5, p.10371044, 2003.

BRATTI, L.F.S.; DITTRICH, J.R.; BARROS, C.S. et al. Comportamento ingestivo de caprinos em pastagem de azevém e aveia-preta em cultivo puro e consorciado. Ciência Animal Brasileira, v.10, n.2, p.397-405, 2009.

BURNS, J.C.; LIPPKE, H.; FISHER, D.S. The relationship of herbage mass and characteristics to animal responses in grazing experiments. In: MARTEN, G.C. (Ed.) Grazing research: design, methodology and analysis. Madison: Crop Science Society of America, 1989. p.07-19.

COOK, C.W.; THORNE, J.L.; BLAKE, J.T. et al. Use of an esophageal-fistula cannula for collecting forage samples by grazing sheep. Journal of Animal Science, v.17, n.1, p.189193, 1958.

DITTRICH, J.R.; CARVALHO, P.C.F.; DITTRICH, R.L. et al. Comportamento ingestivo de eqüinos em pastagens. Archives of Veterinary Science, v.12, n.3, p.1-8, 2007.

EMPRESA BRASILEIRA DE PESQUISA AGROPECUÁRIA - EMBRAPA. Sistema Brasileiro de Classificação de Solo. Brasília: EMBRAPA, 1999. 412p.
FEROLLA, F.S.; VÁSQUEZ, H.M.; SILVA, J.F.C. et al. Composição bromatológica e fracionamento de carboidratos e proteínas de aveia-preta e triticale sob corte e pastejo. Revista Brasileira de Zootecnia, v.37, n.2, p.197-204, 2008.

GARDNER, A.L. Técnicas de pesquisa em pastagens e aplicabilidade de resultados em sistemas de reprodução. Brasília: IICA / EMBRAPA - CNPGL, 1986. 197p.

HARRISON, F.A. Surgical Techniques in Experimental Farm Animals. New York: Oxford Universty Press Inc., 1995. 159p.

LUCZYSZYN, V.C.; ROSSI JUNIOR, P. Composição bromatológica de pastagens de inverno submetidas a pastejo por ovinos, obtidas por fístulas esofágicas. Revista Acadêmica Ciências Agrárias e Ambientais, v.5, n.4, p.345-351, 2007.

MACARI, S.; ROCHA, M.G.; RESTLE, J. et al. Avaliação da mistura de cultivares de aveia preta (Avena strigosa Schreb) com azevém (Lolium multiflorum Lam.) sob pastejo. Ciência Rural, v.36, n.3, p.910-915, 2006.

PACIULLO, D.S.C. Características anatômicas relacionadas ao valor nutritivo de gramíneas forrageiras. Ciência Rural, v.32, n.2, p.357-364, 2002.

PEREIRA, J.R.A.; ROSSI JUNIOR, P. Manual prático de avaliação nutricional de alimentos. Piracicaba: FEALQ, 1995. 34p.

RIBEIRO, T.M.D.; MONTEIRO, A.L.G.; PRADO, O.R. et al. Desempenho e características das carcaças de cordeiros em quatro sistemas de produção. Revista Brasileira de Saúde e Produção Animal, v.10, n.2, p.366-378, 2009.

SANTOS, G.R.A.; BATISTA, A.M.V.; GUIM, A. et al. Composição química e degradabilidade in situ da ração em ovinos em área de caatinga no sertão de Pernambuco. Revista Brasileira de Zootecnia, v.38, n.2, p.384-391, 2009.

SILVA, C.J.A.; DITTRICH, J.R.; MONTEIRO, A.L.G. et al. Preferência de caprinos em pastejo: efeito da altura dos dosséis das forrageiras aruana e hemártria. Ciência Animal Brasileira, v.10, n.3, p.698-710, 2009.

TILLEY, J.A.M.; TERRY, R.A. A two-stage technique for the in vitro digestion of forage crops. Journal of the British Grassland Society, v.18, n.2, p.104-111, 1963.

TREVISAN, N.B.; QUADROS, F.L.F.; SILVA, A.C.F. et al. Comportamento ingestivo de novilhos de corte em pastagem de aveia preta e 
azevém com níveis distintos de folhas verdes.

Ciência Rural, v.34, n.5, p.1543-1548, 2004.

TRINDADE, J.K.; SILVA, S.C.; SOUZA JÚNIOR, S.J. et al. Composição morfológica da forragem consumida por bovinos de corte durante 0 rebaixamento do capim-marandu submetido a estratégias de pastejo rotativo. Pesquisa Agropecuária Brasileira, v.42, n.6, p.883-890, 2007. 